\title{
Anti-Proliferative Effects of the Methanolic Extract of Kedrostis Foetidissima in Breast Cancer Cell Lines
}

\author{
Mpho Choene and Lesetja R. Motadi* \\ School of Molecular and Cell Biology, University of the Witwatersrand, Private Bag 3 WITS 2050, South Africa
}

\begin{abstract}
Traditional plants have been a great source of medicine in developing countries, such as African countries, India and China. But in the $20^{\text {th }}$ century, scientists in both developed and developing countries have been growing interest in medicinal plants due to their observed antibacterial and anti-proliferative properties. Accordingly, the study was aimed to investigate possible anti-proliferative effects of $\mathrm{K}$. foetidissima that are associated with the potential anticarcinogenic properties in breast cancer. MCF-7 and YMB-1 cell lines were exposed to different concentrations (0-100 $\mu \mathrm{g} / \mathrm{ml}$ ) of the crude methanolic extract to evaluate their growth inhibitory and apoptosis inducing effects. The extract elicited a dose- and time-dependent inhibition of cell proliferation, followed by a concomitant decrease in cell viability. The observed cytotoxicity was linked to the induction of apoptosis as determined by biochemical features known to be associated with the advent of apoptosis. Real time quantitative RT-PCR of p53 and Retinoblastoma Binding Protein 6 (RBBP6) exhibited aberrant expression profiles of these genes under various treatment conditions. Taken together, the data suggest that the crude methanolic extracts contains bioactive compounds that may be beneficial in the treatment of breast cancer, and that this apparent antineoplastic activity is a consequence of anti-proliferation rather than a particular molecular mechanism associated with the above genes.
\end{abstract}

Keywords: Apoptosis, Breast cancer, Anti-proliferation, RBBP6 and p53

\section{Introduction}

In South Africa, $70-80 \%$ of the black population consult with traditional healers as a source of primary healthcare. Traditional healers use various traditional indigenous plants to heal different ailments. South Africa has a rich flora biodiversity, comprising of about $8 \%(20,000)$ of the world's plant species. Of these, about $20 \%$ (3689) are used therapeutically [1]. Healers either use the roots, stems or leaves of individual plants or combinations of a number of them. However, a great number of people harvest their own plants or obtain them from local muthi vendors. The obstacle faced however, is little or no knowledge on the molecular mechanisms of active compounds and the chemical profiles of these plants. Hence, it is imperative for those plants which have been used traditionally as medicine for treatment of various diseases, that they undergo pharmacological and biological studies to test for their activities and efficacy.

One such plant is Kedrostis foetidissima, also called Utuvishe in Xhosa. It belongs to a group of plants known as cucurbitacins. Cucurbitacins are a group of bitter tasting plants mostly found in the plant family Curcubitaceae. The characteristic constituent of this family of plants are cucurbitacins, these are tetracyclic triterpenoids derived from the skeleton of these plants. Cucurbitacins are all named after successive letters of the alphabet from A to R. A previous study identified cucurbitacins B, D, E and I as present in K. foetidissima [2,3]. The distribution of $K$. foetidissima stems in the southern African region including Namibia, Botswana through to Gauteng, KwaZulu-Natal, Limpopo, Mpumalanga, Northwest and Northern Cape [South African National Biodiversity Institute (SANBI)].

Normal breast tissue is characterised by a controlled balance between cell proliferation and apoptosis. Apoptosis is a form of programmed cell death; it is a normal physiological process in multicellular organisms which is important for maintaining homeostasis by ensuring a balance between proliferation of normal cells and non inflammatory death of damaged cells which is mediated by caspases [4]. There has been a lot of evidence linking breast malignancies not only to uncontrolled proliferation but to defects in apoptosis [5]. Defects in apoptosis may result from loss or inactivation of positive regulators of apoptosis or upregulation of inhibitor of apoptosis proteins (IAPs). IAPs are caspase inhibitors with the ability to bind on different regions of caspases, these have been found to be over expressed in many cases of breast cancer [6]. Apoptosis is initiated by two major pathways the intrinsic and the extrinsic pathways [7]. The intrinsic pathway, being the most involves mitochondrial membrane. This pathway is induced by stimuli resulting from either intracellular or extracellular stress caused by cellular damage [8].

There are a number of regulatory proteins that have been implicated in influencing cells to undergo apoptosis, however, there are two key regulatory proteins that have been largely conserved in species; they exist as multigene families with multiple homologs. They are known as Bcl-2 (family of inhibitors and promoters of apoptosis) and the p53 tumour suppressor gene and both have been extensively researched in breast cancer [5]. DNA damage could activate p53 which may act as an inducer of apoptosis [9]. Cytochrome $\mathrm{c}$ is released from the mitochondria leading to a cascade of caspase activation, apoptosis is then triggered through the pro apoptotic Bcl-2 gene family and protease caspase-9 [10]. The extrinsic pathway involves cell surface death receptors, when a ligand binds to members of the TNF- $\alpha$ super family of receptors caspase 8 and 10 are recruited and activated to form the death inducing signalling complex [7].

\section{Materials and Methods}

\section{Reagents}

RPMI-1640 media and Foetal Bovine Serum (FBS) were purchased

*Corresponding author: Lesetja Raymond Motadi, School of Molecular and Cell Biology, University of the Witwatersrand, Private Bag 3, Wits, South Africa, Tel: +2711 7176485 Fax: +2711717 6351; E-mail: lesetja.motadi@wits.ac.za

Received May 23, 2012; Accepted June 08, 2012; Published June 13, 2012

Citation: Choene M, Motadi LR (2012) Anti-Proliferative Effects of the Methanolic Extract of Kedrostis Foetidissima in Breast Cancer Cell Lines. Mol Biol 1:107. doi:10.4172/2168-9547.1000107

Copyright: ( $) 2012$ Choene M, et al. This is an open-access article distributed under the terms of the Creative Commons Attribution License, which permits unrestricted use, distribution, and reproduction in any medium, provided the original author and source are credited. 
from Highveld Biologicals (Pty) Ltd, Lyndhurst, South Africa. Penicillin, streptomycin, neomycin (PSN) antibiotic cocktail from Gibco, Auckland, New Zealand. Monoclonal IgG primary antibodies, Goat anti-mouse IgG-HRP conjugated secondary antibodies, and Western blotting luminol reagent from Santa-Cruz, Biotechnology Inc., USA. DMSO and Tween-20 from Merck Laboratory Suppliers (Pty). Sodium dodecyl-sulphate (SDS), BDH Laboratory Suppliers. Phenylmethylsulfonyl Fluoride (PMSF) from Boehringer-Mannheim, Germany. Bromophenol blue, Coomassie blue R200, Sodium chloride, Ethanol, and Methanol from Saarchem (Pty) Ltd, South Africa.

\section{Cell culture}

The breast cancer (MCF-7 and YMB-1) cells were cultured in DMEM/RPMI-1640 medium supplemented with 10\% Fetal Bovine Serum (FBS), $100 \mathrm{U} / \mathrm{ml}$ penicillin, and $100 \mu \mathrm{g} / \mathrm{ml}$ streptomycin. Incubation was carried out at $37^{\circ} \mathrm{C}$ with an atmosphere of $5 \% \mathrm{CO}_{2}$.

\section{Preparation of crude extract}

The herbal extract used in this study: Kedrostis foetidissima, was obtained from Limpopo Province (South Africa). The stems and leaves were collected, washed and frozen. The frozen plant materials were minced in liquid nitrogen using a warring blender. Once ground, the plant materials were weighed and extracted using absolute methanol $(1 \mathrm{~g} / 10 \mathrm{ml}, \mathrm{w} / \mathrm{v})$ at room temperature for 24 hours. The resulting extract was filtered through a Whatman filter paper, and then the filtrate was dried at $40^{\circ} \mathrm{C}$ under low pressure using a Büchi rotavapor R-205 (Büchi Labortechnik AG, Switzerland). Once dried, the extract was weighed and dissolved in $100 \%$ dimethyl sulfoxide (DMSO) to the desired concentration and stored as a stock solution in an airtight container at $-20^{\circ} \mathrm{C}$ until use.

\section{MTT assay}

The MTT (3-(4,5-dimethylthiazol-2-yl)-2,5-diphenyl tetrazolium bromide) assay is a simple colorimetric assay used to measure cell cytotoxicity, proliferation or viability. MTT is a pale yellow substrate which reacts with live cells to produce a dark blue formazan, the formazan requires alcohol to dissolve, and this can then be measured on a spectrophotometer [11]. This assay was used to measure plant methanol extract effect on breast cancer cell viability. Ninety six well tissue culture plates were used to culture cells for the MTT assay. Into each well, $5 \times 10^{3}$ cells in $90 \mu \mathrm{l}$ of media were seeded. These were then incubated overnight. Cells were treated with varying concentrations of the herbal extracts $(10,30,50$ and $100 \mu \mathrm{g} / \mathrm{ml})$; a non treatment control and a blank were included. Cells were treated over a period of 24 hours. Following the required treatment time, $10 \mu \mathrm{l}$ of MTT (prepared to $5 \mathrm{mg}$ / $\mathrm{ml}$ PBS) was added to each well except for the blank, these were further incubated for 4 hours. To dissolve the formazan crystals formed, $90 \mu \mathrm{l}$ of DMSO was added and the plate was read using Bio-Rad Microplate reader at an absorbance of $570 \mathrm{~nm}$.

Percentage Cell Viability was calculated as follows:

$\%$ Cell viability $=$ Absorbance of treated cells - Absorbance of blank $\times 100$

Absorbance of untreated cells - Absorbance of blank

\section{Flow cytometry}

Cells were collected and washed twice with PBS. The cells were resuspended in PBS and then fixed using cold ethanol on ice for at least 1 hour. For the measurements of Annexin-V-PI binding, the Annexin V-FITC Apoptosis Detection Kit (BD Biosciences) was used according to the manufacturer's instructions. In brief, the cell pellets were suspended in $100 \mu \mathrm{l}$ of Annexin binding buffer, followed by incubation for $15 \mathrm{~min}$ in the dark with V-FITC and V-PI respectively, and then analysed using the flow cytometry (Becton Dickinson Labware, Franklin Lakes, NJ).

\section{Real Time-PCR analysis}

In order to conduct RT-PCR, total RNA was isolated using roche total RNA extraction kit (Roche, German) as described by the manufacturer's protocol. Reverse transcription was performed using the Impro Reverse Transcriptase (Whitehead, SA). After cDNA was synthesized by using Oligo ( $\mathrm{dT}$ ), the cDNA was amplified by PCR. The specific primers to perform SYBR green-based real-time quantitative PCR were designed as follow: GADPH: Forward - 5'-GAG TCA ACG GAT TTG GTC GT- 3', Reverse - 5' -TTG ATT TTG GAG GGA TCT CG- 3'; RBBP6: Forward - 5' -CAG CGA CGA CTA AAA GAA GAG TCT- 3', Reverse - 5' - GGT AAT TGC GGC TCT TGC CT$3^{\prime}$ and P53: Forward - 5' -GTT CCG AGA GCT GAA TGA GG- $3^{\prime}$, Reverse $-5^{\prime}$-TGA GTC AGG CCC TTC TGT CT $-3^{\prime}$. The thermal profile used was as follows: $50^{\circ} \mathrm{C}$ for $30 \mathrm{~min}, 95^{\circ} \mathrm{C}$ for $10 \mathrm{~min}$ and 45 cycles of $95^{\circ} \mathrm{C}$ for $15 \mathrm{~s}, 55^{\circ} \mathrm{C}$ for $1 \mathrm{~min}$ and $72^{\circ} \mathrm{C}$ for $30 \mathrm{~s}$. The reactions were done in duplicate. The scale bars represent the standard error of mean. The resulting gene mRNA data were normalized against the reference gene (GAPDH) mRNA and compared to the untreated cells of the appropriate strain for relative expression values.

\section{Immuno blot analysis}

Total cell lysate extraction were carried out as previously as follows: cells were lysed in cytosolic buffer $10 \mathrm{mM}$ HEPES-KOH pH 7.9, 10 $\mathrm{mM} \mathrm{KCl}, 2 \mathrm{mM} \mathrm{MgCl}, 0.2 \mathrm{mM} \mathrm{NaF}, 0.1 \mathrm{mM}$ EDTA, $0.1 \mathrm{mM} \mathrm{Na}_{3} \mathrm{VO}_{4}$, and $1 \mathrm{mM} \mathrm{DTT}$ ) containing protease inhibitors. After addition of NP40 to a final concentration of $0.15 \%$, the lysate was vigorously mixed for $15 \mathrm{~s}$ and then centrifuged at $12,000 \mathrm{rpm}$ for $1 \mathrm{~min}$ at $4^{\circ} \mathrm{C}$. The resulting supernatant was store at $-80^{\circ} \mathrm{C}$ as the cytoplasmic extract. Total lysates were prepared by RIPA buffer containing $50 \mathrm{mM}$ Tris $(\mathrm{pH}$ 7.5), $150 \mathrm{mM} \mathrm{NaCl}, 1 \%$ NP40, 0.1\% SDS, 0.5\% SDC, 1 mM EDTA, 1 mM EGTA, $1 \mathrm{mM}$ orthovanadate, aprotinin $(10 \mu \mathrm{g} / \mathrm{ml})$ and $0.4 \mathrm{mM}$ phenylmethylsufonyl fluoride (PMSF). Collected cells were maintained for $1 \mathrm{~h}$ in RIPA buffer and after centrifugation at 12,000 rpm for $30 \mathrm{~min}$ at $4^{\circ} \mathrm{C}$, the supernatant was collected and preserved at $-80^{\circ} \mathrm{C}$ until use. Equal amounts $(60 \mu \mathrm{g} / \mu \mathrm{l})$ of total cell lysate was subsequently applied to SDS-PAGE and transferred into Poly-Vinylidene Difluoride (PVDF) membrane (Millipore, Billerica, MA). The membrane was blocked with 5\% skimmed milk for overnight and then incubated with specific antibodies. After washing with PBS containing 0.05\% Tween-20 (PBST), the membrane was reacted with Horseradish Peroxidase (HRP) conjugated secondary antibody. The immune complex in PVDF membrane was detected with Enhanced Chemiluminescence (ECL) solution (Amersham Bioscience, Buckinghamshire, UK) and X-ray.

\section{Statistical analysis}

The results of each series of experiments (performed in triplicates) are expressed as the mean values \pm standard deviation of the mean (SD). Levels of the statistical significance were calculated using the paired student $t$-test when comparing two groups, or by analysis of variance (ANOVA). P-values of 0.05 were considered significant.

\section{Results}

Effect of Kedrostis foetidissima extracts on breast cancer cell lines MCF-7 and YMB-1

To examine the effect of K.foetidissima extracts on the growth of 
MCF-7 and YMB-1 cells, a cell viability assay using MTT assay was performed with various concentrations of $K$. foetidissima for 12; 24 and 48 h. K. foetidissima inhibited MCF-7 and YMB-1 cell growth in a time and dose-dependent manner. At $48 \mathrm{~h}$, the proliferation of MCF-7 and YMB- 1 cells was significantly inhibited at $48 \%$ and $55 \%$ respectively at a concentration of $100 \mathrm{ug} / \mathrm{ml}$ (Figure $1 \mathrm{~A} \&$ Figure 1B). Also, we observed chromosomal DNA cleavage and apoptotic body, which are features of apoptosis. DNA fragmentation was observed after treatment with $K$. foetidissima for $48 \mathrm{~h}$ (Figure 2). To confirm apoptosis, we performed flow cytometer and Western blotting to identify the p53 and RBBP6 expression levels in K. foetidissima-treated MCF-7 and YMB-1 cells.

\section{Induction of apoptosis by $K$. foetidissima}

To confirm the effects of $K$. foetidissima on apoptosis, MCF-7 and YMB-1 cells were treated with or without $K$. foetidissima for $48 \mathrm{~h}$ and cell cycle distribution were measured by FACS analysis. We assessed the effect of K. foetidissima on induction of apoptosis in MCF-7 and YMB-1 cells using a dual staining approach with Propidium Iodide (PI) and Annexin V. Annexin V positive/PI negative (early apoptosis) and Annexin $\mathrm{V}$ positive/PI positive (late apoptosis) cells were increased in K. foetidissima-treated MCF-7 and YMB-1 cells (Figure 3B and Figure3D). The number of both Annexin V positive/PI negative and Annexin V positive/PI positive cells was increased 4-fold at a $100 \mu \mathrm{g} /$ $\mathrm{ml}$ concentration of $K$. foetidissima, compared to the untreated cells (Figure 3A \& Figure 3C).

\section{Expression of p53 and RBBP6 as regulated by $K$. foetidissima}

To predict the mechanism of how K. foetidissima induces apoptosis, we performed a Western blot to determine the expression of a known apoptosis inducing gene p53 and cell proliferating gene RBBP6 (Figure 4). p53 expression in K. foetidissima -treated MCF-7 and YMB-1 cell was slightly up-regulated. The expression of RBBP6 involved in cell proliferation was unchanged in both cell lines treated with $K$. foetidissima. The relative expression levels of p53 in MCF-7 cells following normalisation with $\beta$-actin was 1.05 before treatment. Following treatment with K.foetidissima slightly reduced expression levels to 0.87 folds. While that of RBBP6 was slightly lower to 0.97 from 1.08 folds in MCF-7 treated cells. Similarly, in YMB- 1 in untreated cells the value of $\mathrm{p} 53$ was 1.10 and following treatment it was 0.93 while that of RBBP6 was 1.07 to 0.99 folds following treatment (Figure 5). The herbal extracts K.foetidissima exhibit negligible effect on the expression levels of the tumour suppressors p53 and RBBP6.

\section{Discussion}

Historically, plants, herbs and spices were a folkloric source of medicinal agents, and as modern medicine expanded, many

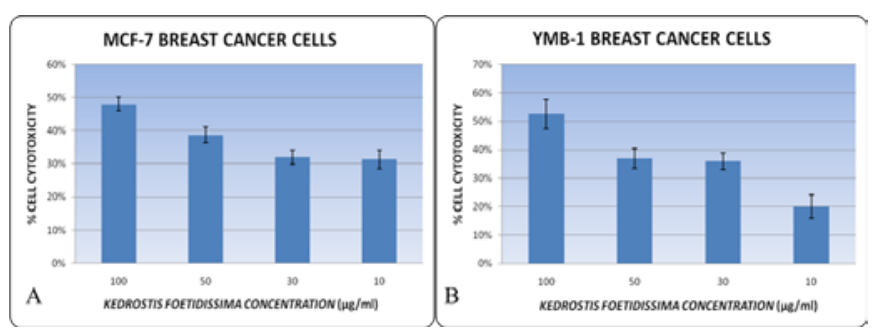

Figure 1: Bar graphs depicting the cytotoxicity of the herbal extracts Kedrostis foetidisima on MCF-7 and YMB-1 breast cancer cells. Cells were treated for 48 hours at increasing concentrations of $10,30,50$ and $100 \mu \mathrm{g} / \mathrm{ml}$ using the plant's methanol extracts. A) At $100 \mu \mathrm{g} / \mathrm{ml}$, a $48 \%$ cell cytotoxicity which is closer to an acceptable IC I $_{50}$ was observed in MCF-7 B) At $100 \mu \mathrm{g} / \mathrm{ml}, 53 \%$ cell cytotoxicity was observed in YMB-1 cells.

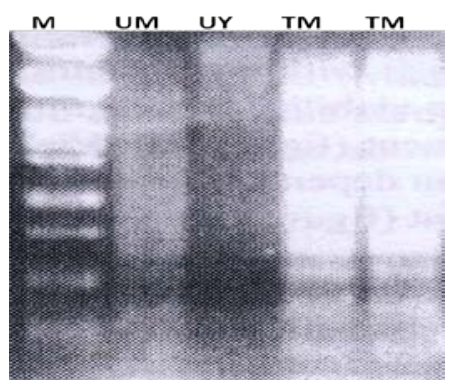

Figure 2: DNA fragmentation in MCF-7 and YMB-1 cells following treatment with K. foetidissima. Agarose gel (1.5\%) electrophoresis demonstrating apoptotic DNA fragmentation. $M$ indicates marker for DNA size. UM= untreated MCF-7 and $U Y=$ untreated $Y M B-1 . T M=$ treated MCF-7 showing fragmented DNA and $\mathrm{TY}=$ treated $\mathrm{YMB}-1$ showing fragmented DNA
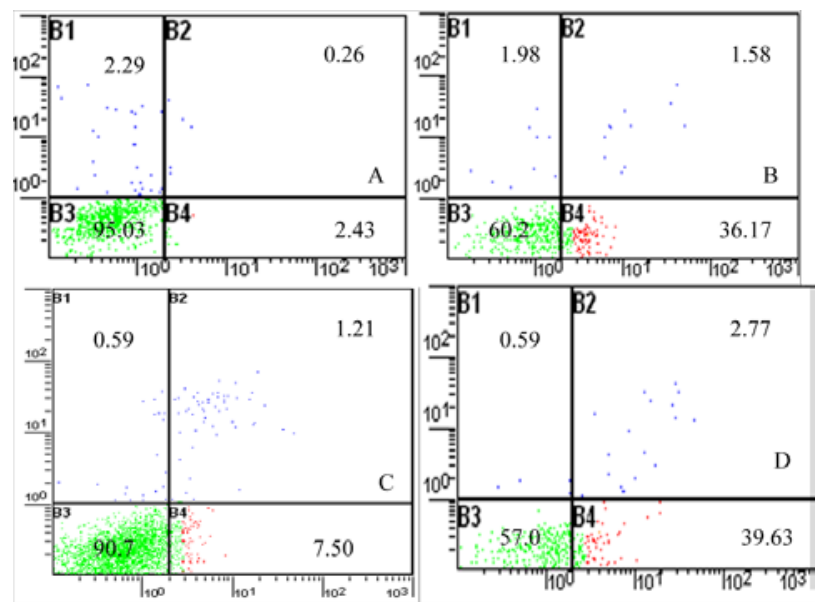

Figure 3: K. foetidissima-induced apoptosis in MCF-7 and YMB-1 cells. Untreated and $K$. Foetidissima $(100 \mu \mathrm{g} / \mathrm{ml})$ treated MCF-7 cells (A\&B). Untreated and $K$. foetidissima $(100 \mu \mathrm{g} / \mathrm{ml})$ treated YMB-1 cells (C\&D). After $48 \mathrm{~h}$, cells were harvested and suspended in binding buffer with annexin V-FITC and propidium iodide $(\mathrm{PI})$, followed by flow cytometry to assess cell apoptosis. B1= positive cells for $\mathrm{PI}$, represents cells undergoing necrosis; $\mathrm{B} 2=$ cells positive for both $\mathrm{PI}$ and Annexin V, represents cells in their late apoptosis; $\mathrm{B} 3=$ unstained cells which are viable and B4= cells positive for Annexin V, represents cells undergo early apoptosis.

useful drugs were developed from lead compounds discovered from medicinal plants. This approach has provided leads against various pharmacological targets, including cancer, malaria and pain, and remains an important route to new pharmaceuticals [1,12]. Recent advances in cytotoxic and phytochemical screening have provided scientists with insight into the bioactive properties of medicinal plants, which has led to the development of new medicines. In this study, $a$ Kedrostis foetidissima plant which is indigenous to South Africa and its neighbouring countries was screened: for its possible anti-proliferative and/or pro-apoptotic effect on two breast cancer cell lines: MCF-7 and YMB-1. The anti-proliferative activity of the herbal plant extracts on the breast cancer cell lines was measured using the $\mathrm{IC}_{50}$ value principle, which is a principle based on the concentration of the plant extract that causes $50 \%$ cell death. The lower the $\mathrm{IC}_{50}$ value of an extract on a cell line, the more potent it is considered to be. The methanol extract of the herbal plant Kedrostis foetidissima exhibited considerable levels of anti-proliferative activity against MCF-7 and YMB-1 breast cancer cells presented in Figure 1. it was observed that $K$. foetidissima extract exhibited a slightly higher cytotoxicity on YMB-1 cells, with $53 \%$ cell cytotoxicity being observed at a concentration of $100 \mu \mathrm{g} / \mathrm{ml}$ 


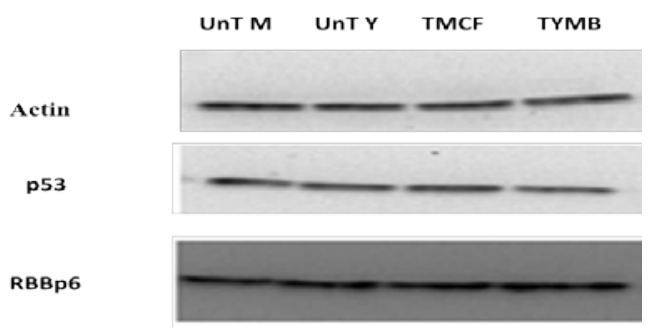

Figure 4: Western blot analysis of some of the main components of the apoptotic machinery. Total protein extracts were performed and $20 \mathrm{mg}$ protein was analysed on a $12 \%$ SDS-PAGE. The results from the western blot show that there was no effect following treatment of both cell lines with $K$. foetidissima $(100 \mu \mathrm{g} / \mathrm{ml})$. UnT $\mathrm{M}=$ untreated MCF-7; UnT $\mathrm{Y}=$ untreated $\mathrm{YMB}-1 ; \mathrm{TMCF}=$ treated MCF-7 and TYMB $=$ treated YMB-1.

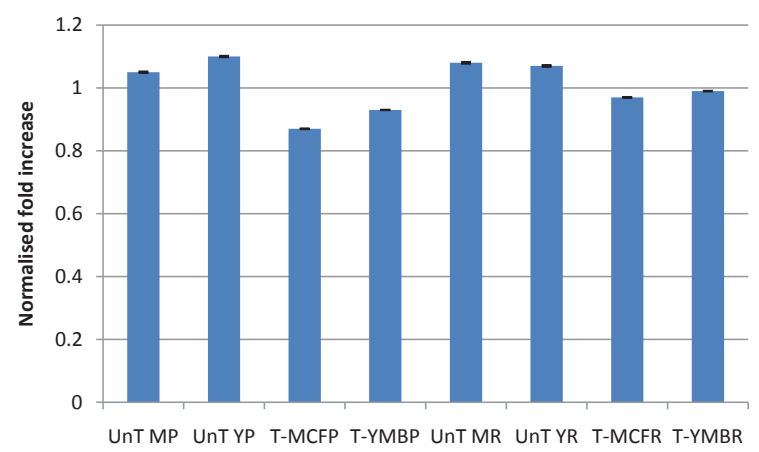

Figure 5: Breast cancer cells were treated with $K$. foetidissima $(100 \mu \mathrm{g} / \mathrm{ml})$ for $48 \mathrm{~h}$. At the indicated time point, p53 and RBBP6 mRNA expression was analysed by quantitative real-time PCR. The levels of amplified p53 and RBBP6 mRNA were normalised to those of GADPH. UnT MP= Untreated MCF-7 for p53, UnT YP= Untreated YMB-1 for p53; T-MCFP= treated MCF-7 for p53; T $\mathrm{YMBP}=$ treated $\mathrm{YMB}-1$ for $\mathrm{p} 53$; UnT MR= Untreated MCF-7 for RBBP6, UnT $Y R=$ Untreated $Y M B-1$ for RBBP6; T-MCFR= treated MCF-7 for RBBP6 and T $Y M B R=$ treated $Y M B-1$ for RBBP6.

and $37 \%$ cytotoxicity at a concentration of $50 \mu \mathrm{g} / \mathrm{ml}$, meaning $50 \mu \mathrm{g} /$ $\mathrm{ml}<\mathrm{IC}_{50}>100 \mu \mathrm{g} / \mathrm{ml}$ (Figure 1A). For MCF-7 cells, an $\mathrm{IC}_{50}>100 \mu \mathrm{g} / \mathrm{ml}$ was observed at a concentration of $100 \mu \mathrm{g} / \mathrm{ml}$ that induced $48 \%$ cell death (Figure 1B).

Kedrostis foetidissima belongs to a large group of plants known as cucurbitacins. Research into anti-proliferative properties of various cucurbitacins has led to interesting discoveries, where cucurbitacins $\mathrm{B}, \mathrm{D}$ and $\mathrm{R}$, isolated from Begonia heracleifolia were found to exhibit cytotoxicity to prostate and nasopharyngeal cancer at $\mathrm{IC}_{50}$ ranging between 0,003 and $3,81 \mu \mathrm{g} / \mathrm{ml}$ [3]. These exhibited a high level of cytotoxicity. For our study, a significant level of cytotoxicity was still induced by $K$. foetidissima on both MCF-7 and YMB-1 cell lines, whose $\mathrm{IC}_{50}$ was at concentrations of between 50 and $100 \mu \mathrm{g} / \mathrm{ml}$ which was in line with other research findings [3]. Another study observed that cucurbitacins B,D,E,I,J,K and L exhibited high cytotoxicity to Hela and $\mathrm{KB}$ human cell cultures with $\mathrm{IC}_{50}$ of $0.005-1 \mu \mathrm{g} / \mathrm{ml}$ [13]. This research and other previous studies are all indicating promising results in the use of cucurbitacins as potential future therapeutics not only of breast cancer but other cancers as well.

Flow-cytometry data with propidium iodide stained cells exhibited increase in apoptotic cells as well as G1 cell cycle arrest. Since $K$. foetidissima seemed to exhibit cytotoxicity on both cell lines, it was then further assessed for possible pro-apoptotic activity on these cell lines.
The YMB-1 cells were treated with $K$. foetidissima at a concentration of $100 \mu \mathrm{g} / \mathrm{ml}$ for 48 hours and tested for markers of apoptosis. Both cell lines treated with $K$. foetidissima extract demonstrated a $40 \%$ phosphatidylserine externalization which is an indication of induced apoptosis (Figure 3B \& Figure 3D). On assessing cells in the second and fourth quadrant representing cells undergoing late and early apoptosis respectively, it was observed that $K$. foetidissima induced slightly higher apoptotic activity in YMB-1 than in MCF-7 cells (Figure 3B \& Figure $3 \mathrm{D}$ ). This difference was also observed in the cytotoxicity assay. It is promising however, that the majority of cells were undergoing apoptosis in both cell lines.

As with all potential anti-tumour agents, it is crucial to understand the molecular mechanism underlying their anti-proliferative activities. The RBBP6 and p53 pathways are related to cell growth, cell cycle arrest, and cell death. The involvement of p53 and apoptosis in the cucurbitacins-mediated effect has been studied in various cancer cells $[2,3]$. In response to various cellular stresses, p53 is phosphorylated on NH2-terminal residues. In particular, the phosphorylation of Ser 15 affects the interaction with the negative regulator MDM2 oncoprotein and enhances contribution to the stabilization of p53 $[14,15]$. Phosphorylation of p53 is mediated by phosphoinositide3-kinase (PI3K)-related proteins, including Ataxia telangiectasiamutated (ATM), ATM- and Rad3- related kinase (ATR) and DNAdependent protein kinases (DNA-PKs). While p53 plays numerous roles in the cell, our experiments focused on distinguishing whether $K$. foetidissima-induced apoptosis was p53 dependent. On the other hand RBBP6 is a negative regulator of $\mathrm{p} 53$ that results in the ubiquitination of p53 thereby leading to cell proliferation [16]. Western blotting for both control and $K$. foetidissima treated cells revealed that p53 was not significantly increased (Figure 4B). Similarly, RBBP6 levels did not differ among the $K$. foetidissima treated and untreated cells (Figure 4C). The biological activities of this plant have not been studied in depth, however, several studies have looked at the molecular mechanisms of different curcubitacins on different cancer cells. Lee et al. [17] reviewed the molecular mechanism of cucurbitacins and gathered that they target different oncogenic signalling pathways that have been implicated in cancer such as the MAPK pathway, JAK-STAT pathway and the AktPKB pathway. The JAK-STAT pathway induces Signal Transducers and Activators of Transcription (STATs) and Janus-Kinases (JAKs). Cucurbitacin B was found to inhibit downstream phosphorylation of some STATs and JAKs in pancreatic tumours, thereby inhibiting this pathway affecting several of its downstream targets involved in apoptosis such as p53 and Bcl-2 [17]. Escandell et al. [18] investigated cucurbitacin R and cucurbitacin I on HCT116 cells harbouring a Ras mutant and found that they induced expression of p53 and p21. They further reported that cucurbitacin $\mathrm{R}$ resulted in $\mathrm{p} 53$ protein over expression and Bcl-2 down regulation following 8,12 and 18 hour treatments in RAW 264.7 macrophages [18].

In summary, the crude extracts of $K$. foetidissima induced apoptosis in both MCF-7 and YMB-1 cells, but, both RT-PCR and Western blot analysis indicated that their mode of action is in a p53 independent manner. Since apoptosis is controlled by such a huge network of genes and signalling molecules, it is possible that these plant extracts control other components of the apoptotic pathway. Further research that incorporates isolation and identification of the active compounds would be required to better understand their molecular mechanism and the molecular pathway that follows this apoptosis induction.

\section{References}

1. Cherry M (2005) South Africa--Serious about Biodiversity Science. PLoS Biol 3: e145. 
2. Miro M (1995) Curcubitacins and their Pharmalogical Effects. Phytother Res 9: 159-168.

3. Rios JL, Escandell JM, Recio MC (2005) New insights into the bioactivity of cucurbitacins. Studies in natural product chemistry 32: 429-469.

4. Kerr JF, Wyllie AH, Currie AR (1972) Apoptosis: A basic biological phenomenon with wide ranging implications in tissue kinetics. Br J Cancer 26: 239-257.

5. Parton M, Dowsett M, Smith I (2001) Studies of apoptosis in breast cancer. BMJ 322: 1528-1532.

6. Nachmias B, Ashhab Y, Ben-Yehuda D (2004) The inhibitor of apoptosis protein family (IAPs): an emerging therapeutic target in cancer. Semin Cancer Biol 14: 231-243.

7. Boatright KM, Salvesen GS (2003) Mechanisms of Caspase Activation. Curr Opin Cell Biol 15: 725-731.

8. Green DR, Kroemer G (2004) The Pathophysiology of Mitochondrial Cell Death. Science 305: 626-629.

9. Kopper L, Petak I (2008) Selected Aspects of Cancer Progression: Metastasis Apoptosis and Immune Response. Cancer Growth and Progression 11: 103113.

10. Purring-Koch C, McLendon G (2000) Cytochrome c binding to Apaf-1: The effects of dATP and ionic strength. Proc Natl Acad Sci U S A 97: 11928-11931.

11. Mosmann T (1983) Rapid colorimetric assay for cellular growth and survival: application to proliferation and cytotoxicity assays. J Immunol Methods 65: 5563.

12. Kale R (1995) Traditional Healers in South Africa: a parallel health care system BMJ 310: 1182-1185.

13. Konopa J, Matuszkiewicz A, Hrabowska M, Onoszka K (1974) Cucurbitacins cytotoxic and antitumor substances from Bryonia alba L. Part II: biological studies. Arzneimittelforsch 24: 1741-1743.

14. Chen LJ, Hsu CC, Hong JR, Jou LK, Tseng HC, et al. (2008) Liver-specific expression of p53-negative regulator $\mathrm{mdm} 2$ leads to growth retardation and fragile liver in zebrafish. Dev Dyn 237: 1070-1081.

15. Suzuki E, Umezawa K, Bonavida B (2007) Rituximab inhibits the constitutively activated PI3K-Akt pathway in B-NHL cell lines: involvement in chemosensitization to drug-induced apoptosis. Oncogene 26: 6184-6193.

16. Motadi LR, Bhoola KD, Dlamini Z (2011) Expression and function of retinoblastoma binding protein 6 (RBBP6) in human lung cancer. Immnobiology 216: 1065-1073

17. Lee DH, Iwanski GB, Thoennissen NH (2010) Cucu rbitacin: Ancien compound shedding new light on cancer treatment. Scientific World Journa 10: $413-418$.

18. Escandell JM, Recio MC, Giner RM, Manez S, Rios JL (2010) Bcl-2 is a negative regulator of interleukin 1 beta secretion in murine macrophages in pharmacological-induced apoptosis. Br J Pharmacol 160: 1844-1856 